\title{
Erratum to: A new evaluation of the hadronic vacuum polarisation contributions to the muon anomalous magnetic moment and to $\alpha\left(m_{Z}^{2}\right)$
}

\author{
M. Davier ${ }^{1}$, A. Hoecker ${ }^{2}$, B. Malaescu ${ }^{3}$, Z. Zhang ${ }^{1, \mathrm{a}}$ \\ ${ }^{1}$ Laboratoire de Physique des 2 Infinis Iréne Joliot-Curie, Université Paris-Saclay et CNRS/IN2P3, Orsay, France \\ ${ }^{2}$ CERN, 1211 Geneva 23, Switzerland \\ ${ }^{3}$ LPNHE, Sorbonne Université, Paris Diderot Sorbonne Paris Cité, CNRS/IN2P3, Paris, France
}

Published online: 12 May 2020

(C) The Author(s) 2020

Erratum to: Eur. Phys. J. C (2020) 80:241

https://doi.org/10.1140/epjc/s10052-020-7792-2

The original version of this article unfortunately contained a mistake. The following sentence was incorrectly rendered by the typesetter:

"The use of the same inputs with different integration kernels in the calculations induces a correlation of $+44 a_{\mu}^{\text {had,LO }}$ and $\Delta \alpha_{\text {had }}\left(m_{Z}^{2}\right)$ uncertainties."

The correct version is:

"The use of the same inputs with different integration kernels in the calculations induces a correlation of $+44 \%$ between the $a_{\mu}^{\text {had,LO }}$ and $\Delta \alpha_{\text {had }}\left(m_{Z}^{2}\right)$ uncertainties."

The original article has been corrected.

Acknowledgements Funded by SCOAP3.

Open Access This article is distributed under the terms of the Creative Commons Attribution 4.0 International License (http://creativecommons.org/licenses/by/4.0/), which permits unrestricted use, distribution, and reproduction in any medium, provided you give appropriate credit to the original author(s) and the source, provide a link to the Creative Commons license, and indicate if changes were made. Funded by SCOAP3.

Open Access This article is distributed under the terms of the Creative Commons Attribution 4.0 International License (http://creativecomm ons.org/licenses/by/4.0/), which permits unrestricted use, distribution, and reproduction in any medium, provided you give appropriate credit to the original author(s) and the source, provide a link to the Creative Commons license, and indicate if changes were made. Funded by SCOAP ${ }^{3}$.

The original article can be found online at https://doi.org/10.1140/ epjc/s10052-020-7792-2.

a e-mail: zhangzq@lal.in2p3.fr (corresponding author) 